\title{
A Rare Cause of Knee Pain in Gout Patients: Tophi of Patella
}

\author{
Ayhan AŞKIN,,${ }^{1}$ Rahime İNCİ, ${ }^{2}$ Özlem AKAN,,${ }^{1}$ Seçil DEMİRDAL,${ }^{1}$ Korhan BAYRAM ${ }^{1}$ \\ ${ }^{1}$ Department of Physical Medicine and Rehabilitation, Katip Çelebi University Atatürk Training and Research Hospital, İzmir, Turkey \\ ${ }^{2}$ Department of Dermatology, Katip Çelebi University Atatürk Training and Research Hospital, İzmir, Turkey
}

\begin{abstract}
Gout is a monosodium urate crystal deposit disease which generally occurs in middle-aged males and postmenopausal females. It is typically characterized by episodic acute and chronic arthritis, due to deposition of monosodium urate crystals in joints and connective tissue. Palpable deposits of crystals known as tophi may form particularly around joints but also elsewhere. Tophi can present as masses in many different body locations resulting in various clinical problems which are finally understood when the mass is sampled and analyzed. A 60-year-old male chronic tophaceous gout patient admitted to our hospital with complaints of bilateral patellar pain. After clinical, laboratory and radiological assessment, our diagnosis was consistent with patellar involvement of gouty tophi which is rarely seen. In this article, we present the clinical and radiological findings of a patient with bilateral severe patellar pain due to gouty tophi.

Keywords: Gout; patella; tophi.
\end{abstract}

Gout is an inflammatory arthritis precipitated by an inflammatory reaction to monosodium urate crystals in the joint. ${ }^{1}$ Palpable deposits of crystals known as tophi form in the chronic phase of gout and may appear in ears, fingertips, forearms, Achilles tendons, knee joints, patellar tendons, and olecranon bursae. ${ }^{2}$ Several cases with solitary gouty tophus of patella have been reported previously, but to our knowledge, involvement of bilateral patellae without pathological fracture or malalignment was underreported in the literature. ${ }^{3}$ In cases with patellar involvement, patient may experience a variety of symptoms including pain, swelling, tissue mass, and limited range of motion. ${ }^{1,2}$ Herein a patient with bilateral knee and patellar pain due to intraosseous gouty tophus in patellae was presented.

\section{CASE REPORT}

A 60-year-old male patient was admitted to our outpatient clinic with three months history of bilateral knee pain. He stated that pain was initially started at the anterior aspect of the left knee, but gradually involved both knees and patellae. Pain was worse with walking or climbing the stairs. He also defined limited range of motion in both knees. Medical history revealed prostatic hyperplasia and a 20 years history of gout. He was taking colchicine $1 \mathrm{mg}$ daily. There was poor compliance to urate lowering therapy.

On physical examination, there was increased warmth and tenderness in both knees, and bilateral joint deformities and tophi were present on first metatarsophalangeal joints. The passive range-of-motion was normal, but painful in both knees. There was no visible tophus in any place other than the first metatarsophalangeal joints.

Laboratory tests including erythrocyte sedimentation rate, blood biochemistry, rheumatoid factor, anti-cyclic citrullinated peptide, liver function tests, and urinary analysis 

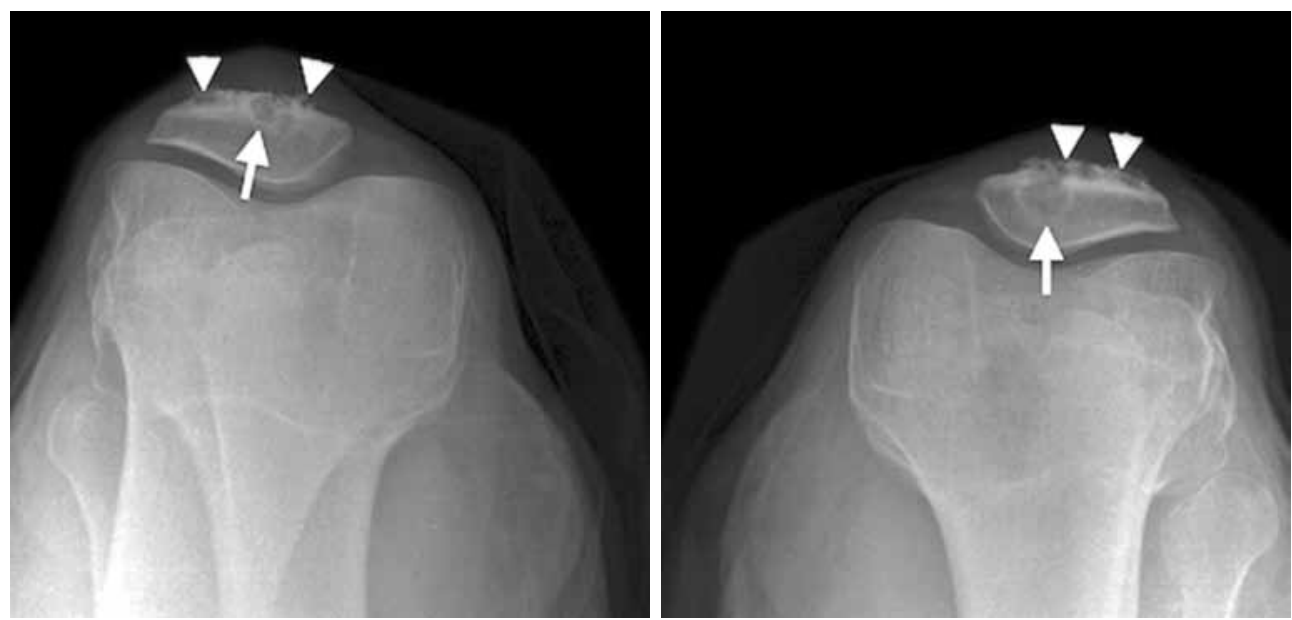

Figure 1. Axial view of plain radiography of right and left knee showed well-defined expansive osteolytic lesion with sclerotic rim at anterior border of both patellae (arrows). Also, cortical erosions and irregularity are seen on anterior contour of both patellae (arrow heads).

were normal except for uric acid value of $7.9 \mathrm{mg} / \mathrm{dL}$ (normal range 2.6-6.0 $\mathrm{mg} / \mathrm{dL}$ ) and C-reactive protein value of $2.1 \mathrm{mg} / \mathrm{dL}$ (normal range $0.01-0.82 \mathrm{mg} / \mathrm{dL}$ ). Roentgenogram revealed lobulated, well-defined expansive osteolytic lesion with sclerotic rim at the anterior border of both patellae. The lesion in the right patella was $2 \times 2.5 \mathrm{~cm}$ and the lesion in the left patella was $3 \times 3 \mathrm{~cm}$ in diameter (Figure 1). Subsequent knee magnetic resonance imaging (MRI) showed bone marrow edema and well-defined expansive soft tissue lesions with low signal intensity on $\mathrm{T}_{1}$-weighted and high signal intensity on $\mathrm{T}_{2}$-weighted images (Figure 2a) in the anterior segments of the both patellae. Sagittal sequences demonstrated
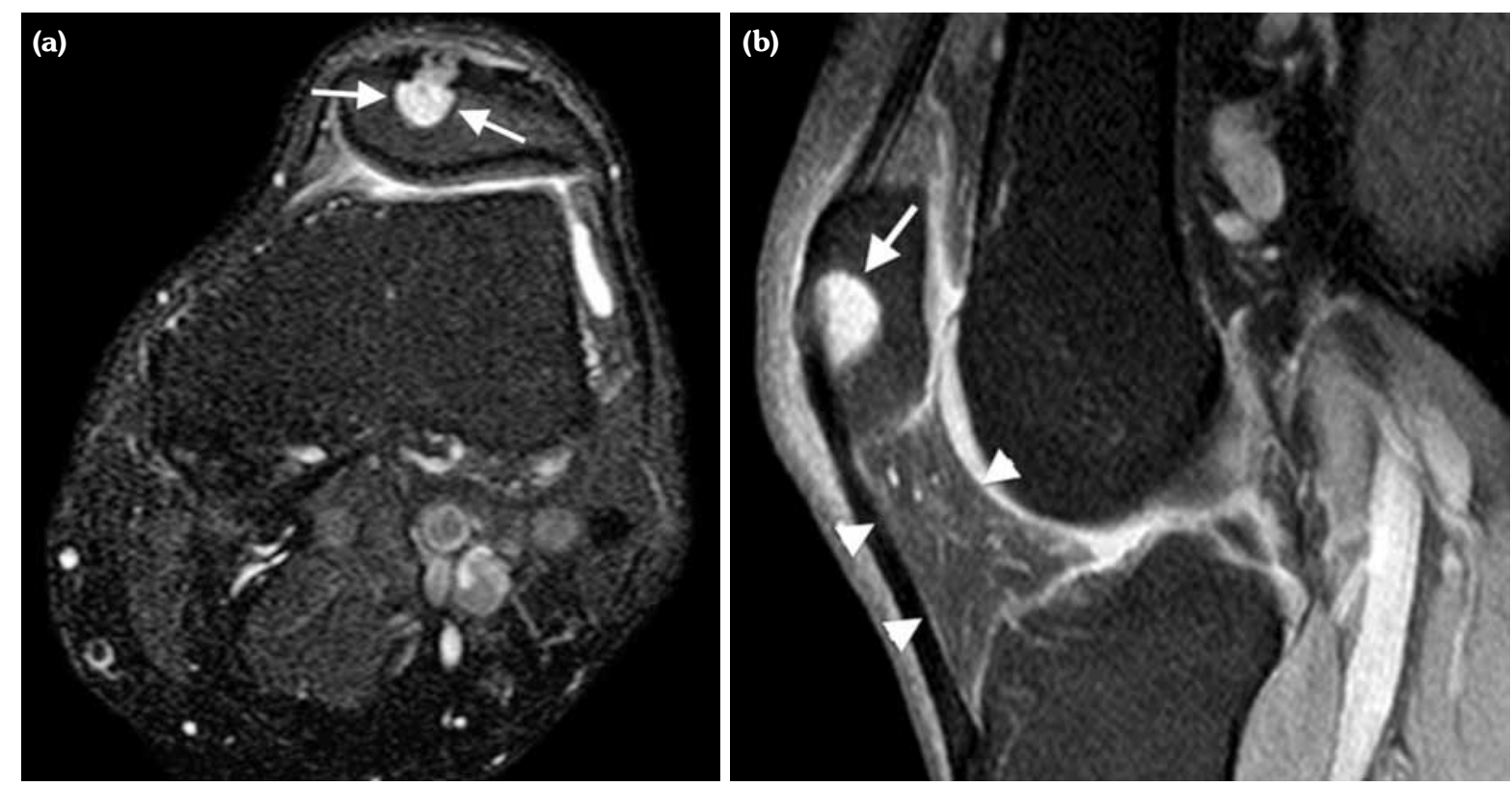

Figure 2. (a) Axial and (b) sagittal view of knee magnetic resonance imaging showed bone marrow edema and well-defined expansive soft tissue lesions had high signal intensity on $\mathrm{T}_{2}$-weighted images in anterior segment of patella (arrows). Sagittal view of knee magnetic resonance imaging also demonstrated thickening and heterogeneous signal intensity in patellar tendon (arrow heads). 
thickening and heterogeneous signal intensity in both patellar tendons (Figure 2b). The diagnosis of gouty involvement of the patella and patellar tendon was established according to the clinical, laboratory, and radiological findings. The patient was treated with colchicine $1 \mathrm{mg} /$ day, and methylprednisolone $8 \mathrm{mg} /$ day. Pain decreased in two weeks and he was able to resume his daily living activities more easily. Allopurinol $300 \mathrm{mg} /$ day was started as urate-lowering therapy. Patient is under follow-up for five months and his serum uric acid level is $5.9 \mathrm{mg} / \mathrm{dL}$.

\section{DISCUSSION}

Tophi are nodules that commonly place in or around the joints, and may be the initial clinical feature of gout. They are usually seen in long standing undiagnosed or improperly treated gout. ${ }^{2}$ The duration of gout and degree of hyperuricemia are correlated with the rate and extent of tophus formation. They usually occur in subcutaneous tissue and can affect any joint of the body. 4

Tophi can present in any location around the knee; however, they are rarely seen on the patellae. Yu et al. ${ }^{5}$ reported seven cases with no visible tophi over the knee joints. The tophi were determined in retro-suprapatellar pouches, infrapatellar fat pad, intercondylar fossae and knee joint. Kobayashi et al. $^{6}$ reported a case who had tophi around the bipartite patella with intraosseous lesion. Ko et al. ${ }^{7}$ evaluated the locations and associated erosions of tophaceous gout in knees of 30 patients and detected only one intraosseous tophus in the patella. Hopper et al. ${ }^{8}$ reported two patients with gouty involvement of patella with pathological fracture and bipartite patella. We were able to find only one case report in the English literature with bilateral lesions of patellae similar to our case. ${ }^{3}$ Recht et al. ${ }^{3}$ reported seven patients who had unilateral or bilateral osteolytic lesions of the patella and analyzed the radiologic characteristics of other osteolytic lesions of the patella.

Bone erosions generally occur at sites of tophi depositions. The pathogenesis of tophus erosion is not clearly understood. However, it has been hypothesized that crystal deposition induces synovitis and produces enzymes contributing to the development of bone erosions. Dalbeth et al. ${ }^{9}$ reported tophus infiltration into bone as the main factor for bone erosion and joint damage in gout. They demonstrated a close relationship between bone erosion and the presence and size of the intraosseous tophus.

Tophi may also form tumor-like masses which make differential diagnosis more important. Patellar gouty tophus can be misdiagnosed as a bone tumor in roentgenogram or MRI scans. ${ }^{10}$ The most common reported pathologies in patients younger than 40 years of age were chondroblastoma and giant cell tumor, while metastatic diseases and gout were the most common for patients over 40 years of age. ${ }^{11}$

Plain radiographic features of gout include soft tissue swelling and bony erosions. These features are generally normal in early gout. ${ }^{4,12}$ MRI is critical for assessing abnormalities in bones, ligaments, and tendons within joints. MRI findings in these patients included bone marrow edema, tophi deposition of patella, and heterogeneous signal intensity in both patellar tendons. These findings are compatible with those of previous studies. ${ }^{6,13}$ Such deposits present as masses with low signal intensity on $\mathrm{T}_{1}$ and intermediate to high signal intensity on $\mathrm{T}_{2}$-weighted images due to the presence of uric acid deposition and associated inflammation..$^{13,14}$ Differential diagnosis also includes chronic rheumatoid arthritis, pigmented villonodular synovitis, chronic infectious arthritis, and amyloidosis. The constellation of clinical and MRI findings often allow the specific diagnosis to be rendered. ${ }^{15}$

To conclude, it is important to bear in mind that tophus of the patella can cause knee pain in patients with gouty arthritis. Early diagnosis and treatment are essential since tophus deposition urges adequate hypouricaemic medical treatment. Patients with tophaceous gout require strict disease control and close follow-up.

\section{Declaration of conflicting interests}

The authors declared no conflicts of interest with respect to the authorship and/or publication of this article. 


\section{Funding}

The authors received no financial support for the research and/or authorship of this article.

\section{REFERENCES}

1. Chen LX, Schumacher HR. Gout: can we create an evidence-based systematic approach to diagnosis and management? Best Pract Res Clin Rheumatol 2006;20:673-84.

2. Falasca GF. Metabolic diseases: gout. Clin Dermatol 2006;24:498-508.

3. Recht MP, Seragini F, Kramer J, Dalinka MK, Hurtgen $\mathrm{K}$, Resnick D. Isolated or dominant lesions of the patella in gout: a report of seven patients. Skeletal Radiol 1994;23:113-6.

4. Richette P, Bardin T. Gout. Lancet. 2010;375:318-28.

5. Yu KH, Lien LC, Ho HH. Limited knee joint range of motion due to invisible gouty tophi. Rheumatology (Oxford) 2004;43:191-4.

6. Kobayashi K, Deie M, Okuhara A, Adachi N, Yasumoto M, Ochi M. Tophaceous gout in the bipartite patella with intra-osseous and intra-articular lesions: a case report. J Orthop Surg (Hong Kong) 2005;13:199-202.

7. Ko KH, Hsu YC, Lee HS, Lee CH, Huang GS. Tophaceous gout of the knee: revisiting MRI patterns in 30 patients. J Clin Rheumatol 2010;16:209-14.

8. Hopper G, Gupta S, Bethapudi S, Ritchie D,
Macduff E, Mahendra A. Tophaceous gout of the patella: a report of two cases. Case Rep Rheumatol 2012;2012:253693.

9. Dalbeth N, Clark B, Gregory K, Gamble G, Sheehan $\mathrm{T}$, Doyle A, et al. Mechanisms of bone erosion in gout: a quantitative analysis using plain radiography and computed tomography. Ann Rheum Dis 2009;68:1290-5.

10. Forbess LJ, Fields TR. The broad spectrum of urate crystal deposition: unusual presentations of gouty tophi. Semin Arthritis Rheum 2012;42:146-54.

11. Singh J, James SL, Kroon HM, Woertler K, Anderson $\mathrm{SE}$, Jundt $\mathrm{G}$, et al. Tumour and tumour-like lesions of the patella--a multicentre experience. Eur Radiol 2009;19:701-12.

12. Barrett K, Miller ML, Wilson JT. Tophaceous gout of the spine mimicking epidural infection: case report and review of the literature. Neurosurgery 2001;48:1170-2.

13. Gerster JC, Landry M, Dufresne L, Meuwly JY. Imaging of tophaceous gout: computed tomography provides specific images compared with magnetic resonance imaging and ultrasonography. Ann Rheum Dis 2002;61:52-4.

14. Oostveen JC, van de Laar MA. Magnetic resonance imaging in rheumatic disorders of the spine and sacroiliac joints. Semin Arthritis Rheum 2000;30:52-69.

15. Gentili A, Sorenson S, Masih S. MR imaging of softtissue masses of the foot. Semin Musculoskelet Radiol 2002;6:141-52. 